\title{
Talking about Height and Quality of Life: A Content-Analysis of Focus Group Discussions with Short-Statured Children and Their Parents in the US
}

\author{
Rachel Sommer ${ }^{*}$, Monika Bullinger1, Andreas Pleil'2, Nelly Mauras ${ }^{3}$, Judith Ross ${ }^{4}$, Ron Newfield ${ }^{5,6}$, \\ Janet Fox ${ }^{2}$, Julia Quitmann¹ \\ ${ }^{1}$ Department of Medical Psychology, Center for Psychosocial Medicine, University Medical Center Hamburg-Eppendorf, Hamburg, \\ Germany \\ ${ }^{2}$ Pfizer Inc., San Diego, CA, USA \\ ${ }^{3}$ Nemours Children's Clinic, Jacksonville, FL, USA \\ ${ }^{4}$ Thomas Jefferson University, Philadelphia, PA, USA \\ ${ }^{5}$ Rady Children's Hospital, San Diego, CA, USA \\ ${ }^{6}$ University of San Diego, San Diego, CA, USA \\ Email: ${ }^{\star}$.sommer@uke.de, bullinger@uke.de, andreas.m.pleil@pfizer.com,NMauras@nemours.org, Judith.Ross@jefferson.edu, \\ rnewfield@rchsd.org, Janet.L.Fox@pfizer.com,j.quitmann@uke.de
}

How to cite this paper: Sommer, R., Bullinger, M., Pleil, A., Mauras, N., Ross, J., Newfield, R., Fox, J. and Quitmann, J. (2016) Talking about Height and Quality of Life: A Content-Analysis of Focus Group Discussions with Short-Statured Children and Their Parents in the US. Open Journa of Endocrine and Metabolic Diseases, 6, 229-241.

http://dx.doi.org/10.4236/ojemd.2016.611027

Received: September 16, 2016 Accepted: November 23, 2016 Published: November 26, 2016

Copyright $\odot 2016$ by authors and Scientific Research Publishing Inc. This work is licensed under the Creative Commons Attribution International License (CC BY 4.0).

\begin{abstract}
Background: To understand what life is like for US children with a diagnosis of Growth Hormone Deficiency or Idiopathic Short Stature, the impact of short stature on Health related Quality of Life (HrQoL) was qualitatively examined and needs for care from the young patients and their parents perspective were identified. Methods: Focus group discussions with 26 American-English speaking and nine AmericanSpanish speaking children and their parents were conducted, transcribed verbatim and subsequently qualitatively analyzed by two independent raters, using an existing coding guideline, based on the multidimensional HrQoL concept and a special software (VERBI-Software MAXQDA 10). Results: A total of 1313 statements for the English-speaking and 447 statements for the Spanish-speaking families were categorized. In the US, the strongest frequency of mention was found for the HrQoL dimension "Social" across respondents, followed by "Treatment" and "Emotion". Conclusion: Conducting and analyzing data generated from focus groups ensure that young patients' experiences of disease are represented in the measure of outcomes for use in clinical trials and patient care.
\end{abstract}

\section{Keywords}

Short Stature, Quality of Life, Children, Focus Groups 


\section{Background}

Health-related Quality of Life (HrQoL) is considered an important health indicator in pediatrics and instruments are increasingly being developed for its assessment [1] [2]. As a multidimensional construct, HrQoL covers physical, emotional, mental, social and behavioral components of well-being and functioning from the perspective of both patients and observers [3]. Health professionals can use the results from HrQoL assessments to understand the burden of disease and the potential effectiveness of treatment from the perspective of the patient with the goal of improving their quality of care [4].

A literature review identified five pediatric condition-specific instruments available for use in children and adolescents with short stature. None of these measures, however, provide full coverage of HrQoL domains potentially influenced by short stature [2]. Therefore the aim of the European Quality of Life in Short Stature Youth (QoLISSY), was to develop and validate a questionnaire to evaluate the impact of short stature on HrQoL in children and adolescents from both the patient and parent perspectives [5] [6].

The QoLISSY questionnaire was originally developed in five European countries (UK, Spain, France, Sweden and Germany) and their respective languages (English, Spanish, French, Swedish and German) as a self-report for children and adolescents eight to eighteen years of age, diagnosed with growth hormone deficiency (GHD) or idiopathic short stature (ISS) and for observer-report by parents of children aged four to eighteen [7]. The current project focuses on the experience of short stature in English- and Spanish-speaking patients in the US.

The objective of this study was to provide evidence for the conceptual appropriateness and practical feasibility of the QoLISSY in US patients diagnosed with GHD and ISS prior to a field test to assess the psychometric performance of the American-English and American-Spanish version of the questionnaire. While information on the development and validation of the US QoLISSY version is available [8], an in-depth qualitative content analysis from the focus group discussions provides rich material for a better understanding of the impact of short stature on the patient's quality of life experience and on their needs for care to improve outcomes.

\section{Health-Related Quality of Life (HrQoL) in Short Stature}

Short stature (SS) is defined as a height of 2.0 or more standard deviations (SD) below the population-specific mean height for age, gender, and nationality. [9]. Endocrine and non-endocrine causes for short stature have been identified, including growth hormone (GH) deficiency (GHD) and idiopathic short stature (ISS) which can be treated with GH replacement [10].

Assessment of HrQoL can help to identify the multi-dimensional burden of short stature and to better tailor interventions and evaluate treatment effects [3]. The assessment of HrQoL in GHD children and adolescents is also important as one of the principal factors determining parents' and patients' likelihood to pursue GH treatment [1].

Understanding the experience of living with short stature involves not only the iden- 
tification of relevant dimensions from the perspective of patients and parents but also an acknowledgement of the cultural background in which respondents live. Some studies found impairments of HrQoL in children and adolescents with short stature [11] [12] [13] [14] [15], while others reported a high HrQoL [16] [17]. Generally, studies with children affected have identified socio-emotional problems and impairments in well-being [6] [18] [19]. Though these problems do not necessarily result in clinical medical problems, some parents report their children to be less socially competent and to have more general problems of a social nature than children with normal height [20]. While clinical studies have shown the effectiveness of GH treatment in increasing height [21] [22] [23] [24] [25], the impact of treatment on HrQoL has still not been thoroughly investigated [26].

\section{The Use of Focus Groups for Understanding Patient Concerns and Developing HrQoL Measures}

A patient-reported outcome (PRO) instrument is defined as the report of health status coming directly from the patient without interpretation of the patient's response by a third party [27] [28]. The range of impact of a health condition is known only to the patients themselves. Direct assessment of the patient perspective is necessary to thoroughly understand a patient's experience of disease and treatment, the impact on their HrQoL and relevant health care needs. Thus, including the perspective of the patient and its family is an important component in the provision of healthcare services [29] [30].

Including the patient and caregivers through the conduct of focus groups and interviews is a key feature within the HrQoL questionnaire development process. A qualitative research methodology that focuses on children/adolescents and their parents' experiences is a necessary first step in developing tools to assess HrQoL outcomes. Qualitative research based on semi-structured interviews is an effective method to elicit experiences, beliefs, points of view, understandings, perceptions, impressions, needs and concerns as well as attitudes from the perspective of the individuals on a specific topic [31] [32].

Individual interviews and focus groups offer the researcher insight into a wide range of views that people have about a specific issue as well as how they discuss and interact on the issue. Conducting focus group interviews is a useful approach, particularly when the researcher may not have an in-depth understanding or knowledge about how a medical condition affects people and the concerns they have regarding their health [33]. Child and parent views may differ and the assessment of HrQoL has been shown to vary depending on the perspective of the person reporting [30]. A review, however, concluded that both child- and parent observer-reports are important and should both be obtained whenever possible to provide the entire perspective [34].

\section{Methods}

The overall aim of the US QoLISSY validation study was to provide an American-Eng- 
lish and an American-Spanish version of the QoLISSY instrument and to evaluate each language version using qualitative and quantitative methods of data collection and analysis. In a first step, focus group discussions for concept elicitation were conducted to examine if the representation of the HrQoL concepts are appropriate for this population. In a second step, a pilot test of the current validated UK English and Spain Spanish questionnaire with a subsequent cognitive interview was performed after a five minute break. Results from the qualitative analysis were used to identify the patient's as well as the parent's needs and concerns regarding the child's short stature and its treatment, based on their own experiences.

Patient recruitment and focus group discussions took place in three pediatric clinical centers across the US between January 2012 and July 2012. Group sessions children with a GHD or ISS diagnosis (age $8-12$ and $13-18$ years and height $<-2.0$ SDS prior to GH treatment) and parents of children ( $4-18$ years) were held separately but in parallel for convenience. Each focus group session ranged in size from three to eight participants and was scheduled to take between 60 to 90 minutes to complete. The sample size was predefined, but depending on saturation regarding results. In- and exclusion criteria were defined as follows:

Inclusion Criteria

- Children with ISS and GHD diagnosis-with no less than -2.25 SD at start of treatment or if currently untreated $-2 \mathrm{SD}$;

- Age groups-4 - 7 (parent only), 8 - 12, and 13 - 18 years AND at least one parent matched to child;

- May be treated with growth hormone from any source or untreated-Must have medical data source documentation available for CRF. Treatment with Genotropin is allowed but not required for participation;

- Attending regular school (i.e., no significant cognitive deficit, have social experience in groups);

- For US English speaking-English must be the primary language spoken in the home and the first language of the parent-children in the 8 and older groups must be able to read English.

Exclusion Criteria

- Significant concomitant medical conditions (including physical and mental health) in either child or parent based on the physician's opinion;

- Critical life events that make it difficult or impossible to participate (such as death of a close relative);

- Subjects may have had prior or ongoing growth hormone therapy with Genotropin or other growth hormone. Those in the treated group must have had at least 6 months of prior treatment and treatment must still be ongoing OR have been treated for no less than 36 months and ceased treatment for any reason.

Group discussions were recorded and transcribed using the transcription software "f4" (Version: v4.2-audiotranskription.de). American-Spanish transcriptions were translated into US-English by two independent psychology and linguistic professionals 
prior to the analysis. The transcripts were sorted according to children/adolescent and parent groups and the names were anonymized so that identification was not possible. Family and individual IDs were assigned to each participant, so that contributions from each participant as well as linked child-parent dyads could be reviewed. The study was approved by an IRB at each site and all participants gave their informed consent and/or assent prior to their participation in the interviews.

Data collected from the focus groups were processed using the "Maximized Qualitative Data Analysis Program" (VERBI-Software MAXQDA 10). A coding guideline was developed that defined the categories, identified the coding rules and provided anchors. The categories were derived from the literature on HrQoL as well as the original QoLISSY project in a deductive fashion. The main function of the qualitative analysis was to code the concepts through the creation of a category system and to allocate individual text elements to a specific category. A category is a main area e.g. "Emotion" with subareas (e.g. worries about height) of the category system. Statements from the focus groups which are allocated (coded) to a specific category are referred to as codings.

The original QoLISSY concept of HrQoL was used to provide a basis for the coding system (see Figure 1). This conceptual model specifies the three core domains of HrQoL, (physical, emotional and social) as well as potential mediators or determinants in terms of coping, beliefs, and treatment. Two additional parent specific domains: concerns regarding the child's future and the impact of short stature of the child on the parent, were used for the categorization exercise from statements elicited in the parent interviews.

Under the supervision from members of the original QoLISSY study group, two independent and trained coders allocated each statement to only one single category, using the same labels from the original European QoLISSY study. The inter-rater agreement

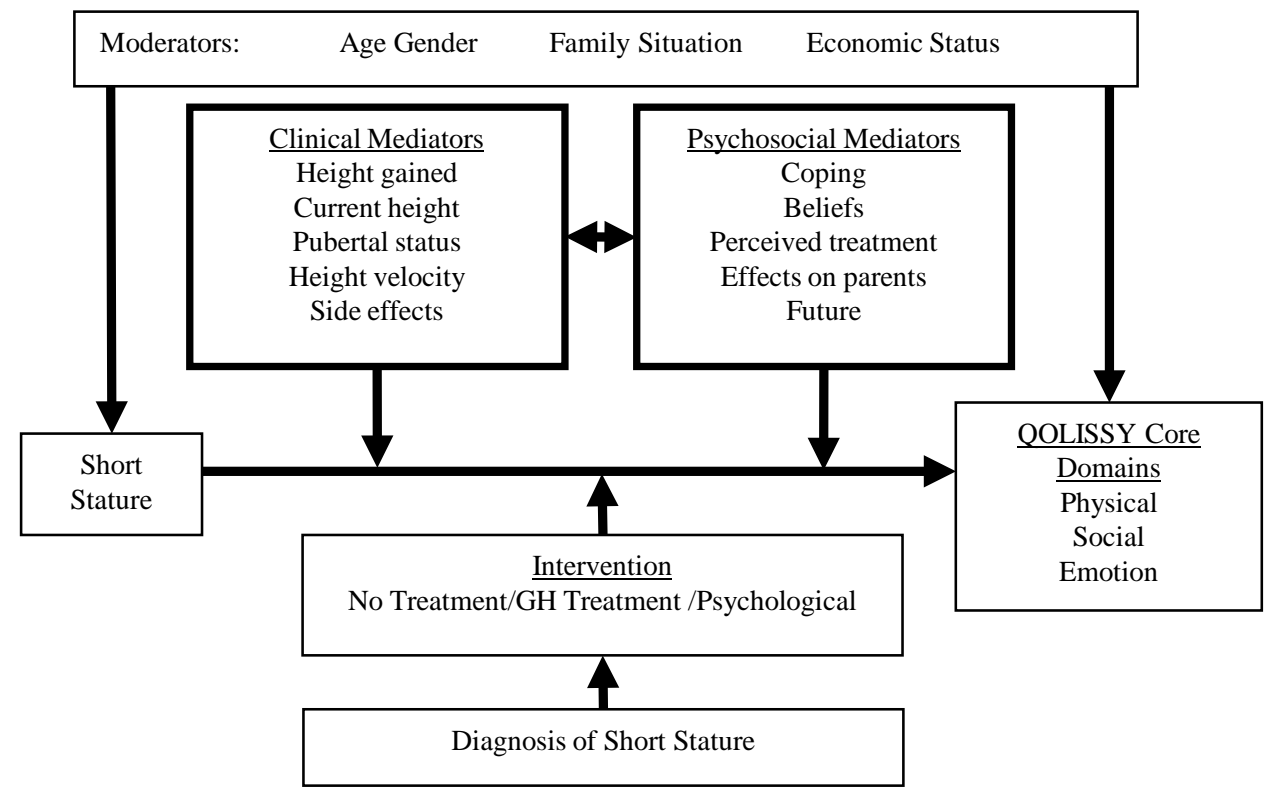

Figure 1. Conceptual model/QOLISSY. 
$(82 \%)$ was calculated in a subset of all interviews in which statements were coded.

\section{Results}

A total of 76 individuals participated in the study: 26 American-English speaking children/adolescents and 30 parents, and nine American-Spanish speaking children/adolescents and 11 of their parents (Table 1). The imbalance is due to the fact that, though conversant in Spanish, many participants used English as their primary language for reading and writing.

In the American-English sample more than half of the children/adolescents were diagnosed with GHD. Almost three quarters of them were receiving or had received GH treatment. The majority of children and adolescents were boys with a mean age of twelve years (SD 2.89). In total four children had reached a height above the -2.0 height standard deviation due to treatment and 20 children were still below the -2.0 height standard deviation of the US national norm for age and gender (Table 1).

The American-Spanish speaking sample consisted of only boys and their parents. The majority of them were diagnosed with GHD. More than half of them were currently or had previously received growth hormone therapy (Table 1).

The transcription of the focus groups yielded 1313 individual statements to be sorted into the pre-defined concept categories identified in the original European QoLISSY

Table 1. Overview focus groups participants.

\begin{tabular}{|c|c|c|c|c|c|c|c|c|c|}
\hline & & & & & \multicolumn{5}{|c|}{ Age group } \\
\hline & & & \multicolumn{2}{|c|}{ Total } & $4-7$ years & \multicolumn{4}{|c|}{$8-12$ years $13-18$ years } \\
\hline & & & Child $(\mathrm{N}=35)$ & Parent $(\mathrm{N}=41)$ & Child $^{* *}$ Paren & tChilc & Paren & tChild & Parent \\
\hline \multirow{4}{*}{ Gender } & \multirow{2}{*}{ Male } & English & 18 & 20 & 2 & 10 & 10 & 8 & 8 \\
\hline & & Spanish & 9 & 11 & 2 & 7 & 7 & 2 & 2 \\
\hline & \multirow{2}{*}{ Female } & English & 8 & 10 & 2 & 7 & 7 & 1 & 1 \\
\hline & & Spanish & 0 & 0 & 0 & 0 & 0 & 0 & 0 \\
\hline \multirow{4}{*}{ Diagnosis } & \multirow{2}{*}{ ISS } & English & 10 & 12 & 2 & 8 & 8 & 2 & 2 \\
\hline & & Spanish & 2 & 3 & 1 & 2 & 2 & 0 & 0 \\
\hline & \multirow{2}{*}{ GHD } & English & 16 & 18 & 2 & 9 & 9 & 7 & 7 \\
\hline & & Spanish & 7 & 8 & 1 & 5 & 5 & 2 & 2 \\
\hline \multirow{4}{*}{ Treatment } & \multirow{2}{*}{ Treated } & English & 19 & 21 & 2 & 10 & 10 & 9 & 9 \\
\hline & & Spanish & 8 & 7 & 1 & 6 & 4 & 2 & 2 \\
\hline & \multirow{2}{*}{ Untreated } & English & 7 & 9 & 2 & 7 & 7 & 0 & 0 \\
\hline & & Spanish & 1 & 4 & 1 & 1 & 1 & 0 & 2 \\
\hline \multirow{4}{*}{ SD height* } & \multirow{2}{*}{$\geq-1.9$} & English & 4 & 4 & 0 & 2 & 2 & 2 & 2 \\
\hline & & Spanish & 4 & 5 & 1 & 3 & 3 & 1 & 1 \\
\hline & \multirow{2}{*}{$\leq-2.0$} & English & 20 & 24 & 4 & 13 & 13 & 7 & 7 \\
\hline & & Spanish & 5 & 6 & 1 & 4 & 4 & 1 & 1 \\
\hline
\end{tabular}

${ }^{\star}$ Data are missing, ${ }^{* *}$ Only parents filled out the questionnaire for children aged $4-7$. 
study. Content analysis of the focus groups statements showed that US children and their parents reported similar concerns and concepts irrespective of language group. Saturation was satisfactory and no new concepts were identified from the US cohort. Table 2 provides the distribution of statement categorizations for the entire cohort.

From the total of 1313 unique statements, 480 were derived from the interviews with children and adolescents and 833 were derived from the parent's statements. Based on the parent interviews, 249 statements were coded to the special parent category "Effects on the parents" which describes the impact of having a child with short stature on the parents themselves. Passages coded from the perspective of the participants are spread across all dimensions of the QoLISSY concept with varying frequencies.

Forty percent (193 statements) of the codings from the American-English children/adolescents interviews were allocated to the dimension "Social". Sixteen percent (79 statements) were coded in the dimension "Emotion", fourteen percent (68 statements)

Table 2. Category system of HrQoL and distribution of codings of children/adolescents and parents across domains.

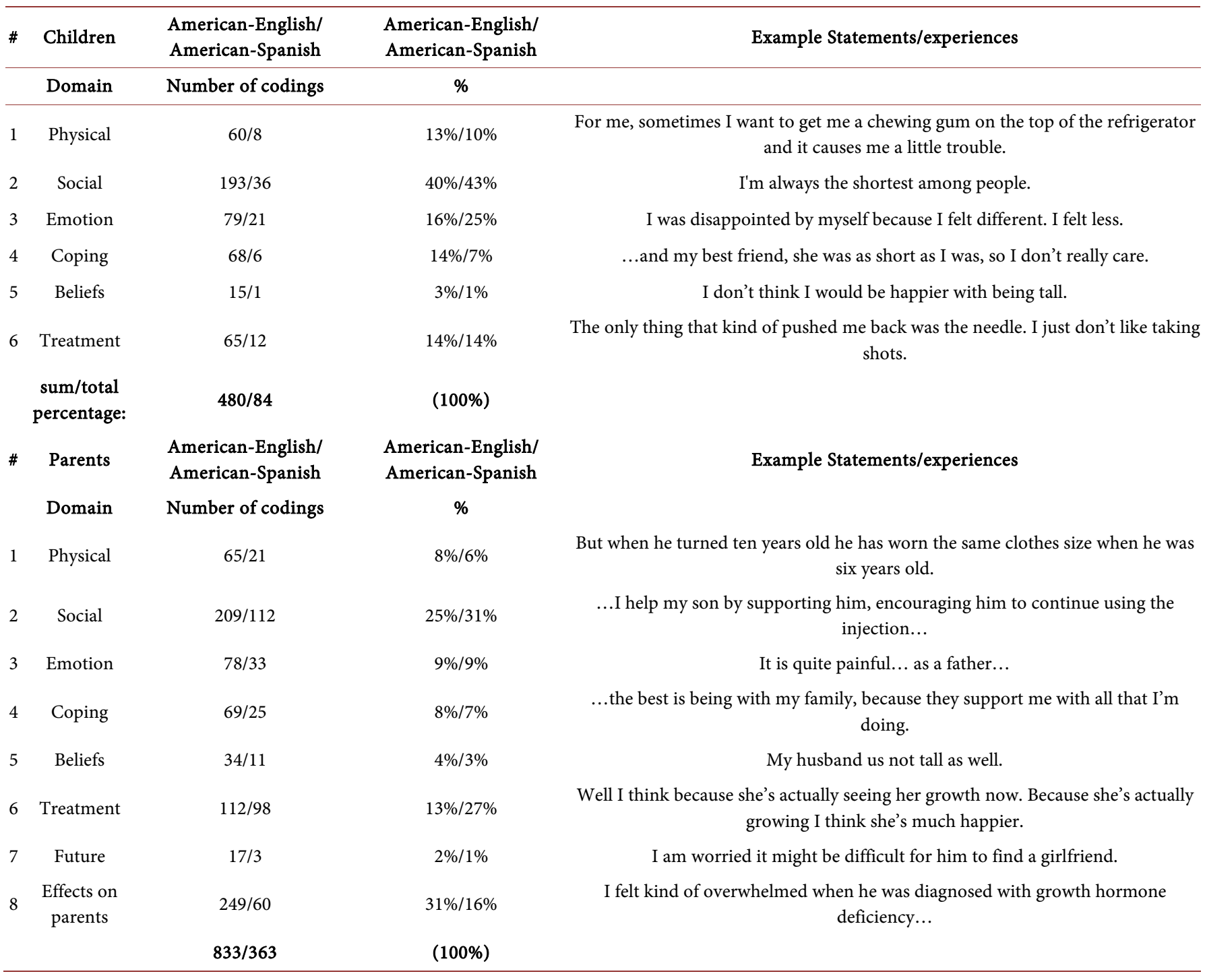


in the dimension "Coping", fourteen percent (65 statements) in the dimension "Treatment" and thirteen percent (60 statements) in the dimension "Physical" (Table 2). The majority of codings in the American-English parent groups (30\% codings, 249 statements of 833 in total) were related to the dimension "Effects on Parents". For the parent interviews, the dimension "Social" (25\%, 209 statements) received the second highest number of all codes.

Analysis of participant statements in the American-Spanish groups yielded a total of 447 codes. Within these, parent's interviews were categorized with a total of 363 coded passages. Children/adolescents most frequently (43\%, 36 statements) referred to social aspects. Likewise, parents attributed most frequently (31\%, 112 statements) their statements to the dimension "Social". The proportion of parent's codes in the dimension "Social" was considerably higher as compared with the other four dimensions (Table 2).

All patient and parent comments and remarks are unedited actual verbatim. The most frequently discussed category "Social" addressed topics like social support and acceptance. Other topics summarized in this category were teasing, bullying, victimization, juvenalization and social interactions in general. The HrQoL dimension "Emotion" contains feelings e.g. worries about height, isolation, emotional suffering, negative affect and embarrassment. The dimension "Coping" was an additional category important for children and adolescents. Topics such as seeking and receiving support were discussed thoroughly by the children, whereas parents most frequently stressed topics like acceptance and ignoring/blocking. The "Treatment" topic was especially important for parents. Within this category, children mostly talked about treatment administration. Parents rather talked about benefits of treatment. "Physical" aspects were infrequently mentioned suggesting a low relevance for the participants themselves. Their parents similarly rarely mentioned physical limitations. Within these category topics like limitation in daily activities was predominantly mentioned. Children/adolescents addressed mainly topics like recreational activities and parents mentioned also problems about clothing. In addition to a view of their children's QoL, the parent interviews

were analyzed in terms of parent-specific issues "Effects on Parents". "Feelings related to growth disorder/height" were mentioned frequently and thus identified as highly relevant for the parents.

Emotional reactions and embarrassment were discussed intensively by the parents and effects of the children's treatment on parents also appeared to be important. Parents also discussed the issue Treatment, their children's diagnosis (GHD/ISS) and the question about attributed cause of short stature.

\section{Discussion}

Children diagnosed with short stature as well as their parents focused on the social aspects of short stature followed by the categories "Emotion" and "Treatment". Discrepancies between the coding frequencies for children/adolescents versus their parents are particularly remarkable in the dimension "Treatment" for the American-English speaking families, with more codes from parents than from their children. This effect 
was also strong for the American-Spanish speaking families with more than twice as many codes on the parents' side than on children/adolescents side. This can be explained by the age of participating children. Since they were rather young, when injections were given by parents they clearly focused on their experiences with the treatment process, related expectations, benefits, and reflections on the health care system.

Overall, the qualitative findings and respective conclusions are consistent with the QoLISSY results in Europe [35]. The results of this study not only support the equivalence of existing concepts and quality of individual items, supporting the instrument's content validity but also the comparable importance of main dimensions of HrQoL across Europe and the US. The emphasis on social and emotional function also suggests that providing psychosocial support in addition to pharmacologic treatment for this patient group should be considered.

Nevertheless, the results of this study must be carefully interpreted, since, particularly for the Spanish cohort, the sample is very small. The difficulty to recruit and conduct focus groups in Spanish language was complicated by the limited Spanish reading and writing abilities of the bilingually educated children and adolescents.

Data, however, provide an insight into the perspectives and needs of children with GHD and ISS and their families and are a useful addition to our understanding of quality of life in short stature. A current opportunity to utilize and further define the appropriateness of items for this HrQoL instrument is in upcoming trials of new long acting formulations of $\mathrm{GH}$ and in the future, in clinical practice.

\section{Conclusions}

This is the first qualitative study involving children with short stature diagnosed with GHD and ISS and their parents in the US, complementing a previous study in Europe [35]. Results are highly informative regarding the patients' needs and concerns especially regarding socio-emotional aspects, which should be respected when identifying options for care.

Studies show that HrQoL in short stature may be enhanced by medical treatments that stimulate growth [15] [36] and HrQoL impairments identified in our clinical populations are real and frequently mentioned. Therefore a combined approach of medical and psychosocial intervention approaches with the aim of improving the patients' and their families' HrQoL might be helpful to individual patients and families.

A challenge for further research is to examine the relationship of height, perceived height, and psychosocial adaptation to HrQoL in short statured children and adolescents in further detail. The aim of such investigations is to better understand what life is like for short statured children and their families and to examine the impact of short stature and its treatment on patient-reported well-being and functioning. The QoLISSY instrument is well positioned as a tool to help meet this objective.

\section{Acknowledgements}

The QoLISSY Project would like to thank the children, parents, and staff from $\mathrm{Ne}$ - 
mours Children's Clinic, Jacksonville, Fl, Thomas Jefferson Nemours Centre, Philadelphia, PA, Rady Children's Hospital and the University of California San Diego, San Diego, CA.

\section{Access to the QoLISSY Instrument}

QoLISSY is a joint initiative between Pfizer Limited and the University Medical Center Hamburg-Eppendorf. Copyright Pfizer Limited all rights reserved. The European QoLISSY instrument, together with comprehensive information of its development and validation process is published in the QoLISSY's User's Manual (Pabst Science Publishers, Lengerich, 2013). The Manual, which is available upon request, includes QoLISSY child and parent forms, as well as scoring information

(http://www.pfizerpatientreportedoutcomes.com/therapeutic-areas/cv-metabolic/endoc $\underline{\text { rine). }}$.

\section{Ethical Standards}

The study has been approved by the appropriate ethics committee and has therefore been performed in accordance with the ethical standard laid down in the 1964 Declaration of Helsinki and its later amendments.

\section{Conflict of Interests}

This study was sponsored by Pfizer, Inc. AP and JF are full time employees of Pfizer Inc. MB, RS, NM, RN, JR and JQ received research funding for the conduct of the study. The authors received no financial support for the development of the manuscript. The QoLISSY Project would like to thank the children, parents, and staff from Nemours Children's Clinic, Jacksonville, FL, Thomas Jefferson Nemours Center, Philadelphia, PA and Rady Children's Hospital and the University of California San Diego, San Diego, CA, and the clinical study staff from Pfizer, particularly Dr. Judith Hey-Hadavi, for their participation and contributions.

\section{References}

[1] Geisler, A., Lass, N., Reinsch, N., et al. (2012) Quality of Life in Children and Adolescents with Growth Hormone Deficiency: Association with Growth Hormone Treatment. Hormone Research in Paediatrics, 78, 94-99. https://doi.org/10.1159/000341151

[2] Brutt, A.L., Sandberg, D.E., Chaplin, J., et al. (2009) Assessment of Health-Related Quality of Life and Patient Satisfaction in Children and Adolescents with Growth Hormone Deficiency or Idiopathic Short Stature-Part 1: A Critical Evaluation of Available Tools. Hormone Research, 72, 65-73. https://doi.org/10.1159/000232158

[3] Ellert, U., Brettschneider, A.-K. and Ravens-Sieberer, U. (2014) Gesundheitsbezogene Lebensqualität bei Kindern und Jugendlichen in Deutschland. Ergebnisse der KiGGS-Studie -Erste Folgebefragung (KiGGS Welle 1). [Health-Related Quality of Life in Children and Adolescents in Germany: Results of the KiGGS Study: First Follow-Up (KiGGS Wave 1)] Bundesgesundheitsblatt-Gesundheitsforschung-Gesundheitsschutz, 57, 798-806. https://doi.org/10.1007/s00103-014-1978-4 
[4] Jahagirdar, D., Kroll, T., Ritchie, K. and Wyke, S. (2013) Patient-Reported Outcome Measures for Chronic Obstructive Pulmonary Disease-The Exclusion of People with Low Literacy Skills and Learning Disabilities. The Patient-Patient-Centered Outcomes Research, 6, 11-21. https://doi.org/10.1007/s40271-013-0004-5

[5] Quitmann, J., Rohenkohl, A., Bullinger-Naber, M., et al. (2014) Parental Perception of Health-Related Quality of Life in Children and Adolescents with Short Stature: Literature Review and Introduction of the Parent-Reported QoLISSY Instrument. Pediatric Endocrinology Reviews, 11, 147-160.

[6] Bullinger, M., Quitmann, J., Power, M., et al. (2013) Assessing the Quality of Life of HealthReferred Children and Adolescents with Short Stature: Development and Psychometric Testing of the QoLISSY Instrument. Health and Quality of Life Outcomes, 11, 76. https://doi.org/10.1186/1477-7525-11-76

[7] Bullinger-Naber, M., Quitmann, J., Silva, N., et al. (2014) Cross-Cultural Equivalence of the Patient- and Parent-Reported Quality of Life in Short Stature Youth Questionnaire (QoLISSY) Questionnaire. Hormone Research in Paediatrics, 82, 18-30. https://doi.org/10.1159/000358832

[8] Bullinger, M., Sommer, R., Pleil, A., et al. (2015) Evaluation of the American-English Quality of Life in Short Stature Youth (QoLISSY) Questionnaire in the United States. Health and Quality of Life Outcomes, 13, 43. https://doi.org/10.1186/s12955-015-0236-2

[9] Rogol, A.D. and Hayden, G.F. (2014) Etiologies and Early Diagnosis of Short Stature and Growth Failure in Children and Adolescents. The Journal of Pediatrics, 164, S1-S14. https://doi.org/10.1016/j.jpeds.2014.02.027

[10] Ergun-Longmire, B. and Wajnrajch, M.P. (2013) Growth and Growth Disorders. In: DeGroot, L., Beck-Peccoz, P., Chrousos, G., et al., Eds., Endotext [Internet]. MD Text.com Inc., South Dartmouth, MA.

[11] Christensen, T.L., Djurhuus, C.B., Clayton, P. and Christiansen, J.S. (2007) An Evaluation of the Relationship between Adult Height and Health-Related Quality of Life in the General UK Population. Clinical Endocrinology, 67, 407-412. https://doi.org/10.1111/j.1365-2265.2007.02901.x

[12] Bannink, E.M., van Pareren, Y.K., Theunissen, N.C., Raat, H., Mulder, P.G. and Hokken-Koelega, A.C. (2005) Quality of Life in Adolescents Born Small for Gestational Age: Does Growth Hormone Make a Difference? Hormone Research, 64, 166-174. https://doi.org/10.1159/000088792

[13] Mobbs, E.J. (2005) The Psychological Outcome of Constitutional Delay of Growth and Puberty. Hormone Research, 63, 2-16.

[14] Sandberg, D.E. and Colsman, M. (2005) Growth Hormone Treatment of Short Stature: Status of the Quality of Life Rationale. Hormone Research, 63, 275-283. https://doi.org/10.1159/000086593

[15] Ross, J.L., Sandberg, D.E., Rose, S.R., et al. (2004) Psychological Adaptation in Children with Idiopathic Short Stature Treated with Growth Hormone or Placebo. Journal of Clinical Endocrinology \& Metabolism, 89, 4873-4878. https://doi.org/10.1210/jc.2004-0791

[16] Sommer, R., Daubmann, A., Quitmann, J., Ravens-Sieberer, U. and Bullinger, M. (2015) Understanding the Impact on Statural Height on Health-Related Quality of Life in German Adolescents: A Population-Based Analysis. European Journal of Pediatrics, 174, 875-882. https://doi.org/10.1007/s00431-014-2480-6

[17] Norby, U., Nordholm, L., Boel, A.-G. and Fasth, A. (2006) Health-Related Quality of Life in Children Diagnosed with Asthma, Diabetes, Juvenile Chronic Arthritis or Short Stature. 
Acta Paediatrica, 95, 450-456.

[18] Abe, S., Okumura, A., Mukae, T., et al. (2009) Depressive Tendency in Children with Growth Hormone Deficiency. Journal of Paediatrics and Child Health, 45, 636-640. https://doi.org/10.1111/j.1440-1754.2009.01586.x

[19] Theunissen, N.C., Kamp, G.A., Koopman, H.M., Zwinderman, K.A., Vogels, T. and Wit, J.M. (2002) Quality of Life and Self-Esteem in Children Treated for Idiopathic Short Stature. Journal of Pediatrics, 140, 507-515. https://doi.org/10.1067/mpd.2002.123766

[20] Visser-van Balen, H., Sinnema, G. and Geenen, R. (2006) Growing Up with Idiopathic Short Stature: Psychosocial Development and Hormone Treatment: A Critical Review. Archives of Disease in Childhood, 91, 433-439. https://doi.org/10.1136/adc.2005.086942

[21] Carel, J., Ecosse, E., Nicolino, M., et al. (2002) Adult Height after Long-Term Recombinant Growth Hormone Treatment for Idiopathic Isolated Growth Hormone Deficiency: Observational Follow-Up Study of the French Population-Based Registry. British Medical Journal, 325, 70-73. https://doi.org/10.1136/bmj.325.7355.70

[22] Carel, J., Chatelain, J., Rochiccioli, P. and Chaussain, J. (2003) Improvement in Adult Height after Growth Hormone Treatment in Adolescents with Short Stature Born Small for Gestational Age: Results of a Randomized Controlled Study. The Journal of Clinical Endocrinology \& Metabolism, 88, 1587-1593. https://doi.org/10.1210/jc.2002-021123

[23] Deodati, A. and Cianfarani, S. (2011) Impact of Growth Hormone Therapy on Adult Height of Children with Idiopathic Short Stature: Systematic Review. British Medical Journal, 342, c7157. https://doi.org/10.1136/bmj.c7157

[24] Cohen, L.E. (2014) Idiopathic Short Stature: A Clinical Review. Journal of the American Medical Association, 311, 1787-1796. https://doi.org/10.1001/jama.2014.3970

[25] Blum, W.F., Ross, J.L., Zimmermann, A.G., et al. (2013) GH Treatment to Final Height Produces Similar Height Gains in Patients with SHOX Deficiency and Turner Syndrome: Results of a Multicenter Trial. The Journal of Clinical Endocrinology \& Metabolism, 98, 1383-1392. https://doi.org/10.1210/jc.2013-1222

[26] Bullinger, M., Koltowska-Haggstrom, M., Sandberg, D., et al. (2009) Health-Related Quality of Life of Children and Adolescents with Growth Hormone Deficiency or Idiopathic Short Stature-Part 2: Available Results and Future Directions. Hormone Research, 72, 74-81. https://doi.org/10.1159/000232159

[27] Patrick, D.L., Burke, B.L., Powers, J.H., et al. (2007) Patient-Reported Outcomes to Support Medical Product Labeling Claims: FDA Perspective. Value in Health, 10, S125-S137. https://doi.org/10.1111/j.1524-4733.2007.00275.x

[28] Food and Drug Administration (2009) Guidance for Industry Patient-Reported Outcome Measures: Use in Medical Product Development to Support Labeling Claims. Food and Drug Administration, Silver Spring.

[29] Schmidt, S., Thyen, U., Chaplin, J., Mueller-Godeffroy, E., Bullinger, M. and European, D.G. (2008) Healthcare Needs and Healthcare Satisfaction from the Perspective of Parents of Children with Chronic Conditions: The DISABKIDS Approach towards Instrument Development. Child: Care, Health and Development, 34, 355-366. https://doi.org/10.1111/j.1365-2214.2008.00815.x

[30] Matza, L.S., Patrick, D.L., Riley, A.W., et al. (2013) Pediatric Patient-Reported Outcome Instruments for Research to Support Medical Product Labeling: Report of the ISPOR PRO Good Research Practices for the Assessment of Children and Adolescents Task Force. Value Health, 16, 461-479. https://doi.org/10.1016/j.jval.2013.04.004

[31] Linhorst, D.M. (2002) A Review of the Use of Potential of Focus Groups in Social Work 
Research. Qualitative Social Work, 1, 208-228.

https://doi.org/10.1177/1473325002001002620

[32] Cohen, D. and Crabtree, B. (2008) Evaluative Criteria for Qualitative Research in Health Care: Controversies and Recommendations. Annals of Family Medicine, 6, 331-339.

https://doi.org/10.1370/afm.818

[33] Jayasekara, R. (2012) Focus Groups in Nursing Research: Methodological Perspectives. Nursing Outlook, 60, 411-416. https://doi.org/10.1016/j.outlook.2012.02.001

[34] Matza, L.S., Swensen, A.R., Flood, E.M., Secnik, K. and Leidy, N.K. (2004) Assessment of Health-Related Quality of Life in Children: A Review of Conceptual, Methodological and Regulatory Issues. Value in Health, 7, 79-92. https://doi.org/10.1111/j.1524-4733.2004.71273.x

[35] Quitmann, J., Rohenkohl, A., Sommer, R., Petzhold, S. and Bullinger, M. (2014) Wie erleben betroffene Kinder und Jugendliche ihren Kleinwuchs, und wie ist die Sicht ihrer Eltern? [How Do Affected Children and Adolescents Experience Their Short Stature, and What Is the Point of View of Their Parents?] Praxis der Kinderpsychologie und Kinderpsychiatrie, 63, 635-648. https://doi.org/10.13109/prkk.2014.63.8.635

[36] Kamp, G.A., Mul, D., Waelkens, J.J., et al. (2001) A Randomized Controlled Trial of Three Years Growth Hormone and Gonadotropin-Releasing Hormone Agonist Treatment in Children with Idiopathic Short Stature and Intrauterine Growth Retardation. The Journal of Clinical Endocrinology \& Metabolism, 86, 2969-2975.

https://doi.org/10.1210/jc.86.7.2969

Submit or recommend next manuscript to SCIRP and we will provide best service for you:

Accepting pre-submission inquiries through Email, Facebook, LinkedIn, Twitter, etc.

A wide selection of journals (inclusive of 9 subjects, more than 200 journals)

Providing 24-hour high-quality service

User-friendly online submission system

Fair and swift peer-review system

Efficient typesetting and proofreading procedure

Display of the result of downloads and visits, as well as the number of cited articles

Maximum dissemination of your research work

Submit your manuscript at: http://papersubmission.scirp.org/

Or contact ojemd@scirp.org 